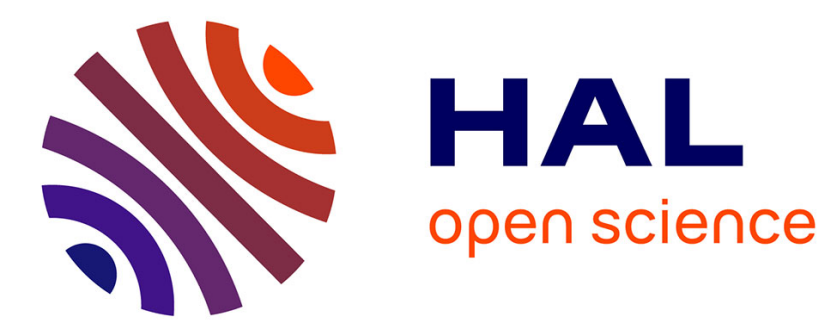

\title{
Synthetic genes specifying periodic polymers modelled on the repetitive domain of wheat gliadins: conception and expression
}

Khalil Elmorjani, M. Thiévin, Thierry Michon, Yves Popineau, J.N. Hallet

\section{- To cite this version:}

Khalil Elmorjani, M. Thiévin, Thierry Michon, Yves Popineau, J.N. Hallet. Synthetic genes specifying periodic polymers modelled on the repetitive domain of wheat gliadins: conception and expression. Biochemical and Biophysical Research Communications, 1997, 239, pp.240-246. hal-02691300

\section{HAL Id: hal-02691300 \\ https: / hal.inrae.fr/hal-02691300}

Submitted on 1 Jun 2020

HAL is a multi-disciplinary open access archive for the deposit and dissemination of scientific research documents, whether they are published or not. The documents may come from teaching and research institutions in France or abroad, or from public or private research centers.
L'archive ouverte pluridisciplinaire HAL, est destinée au dépôt et à la diffusion de documents scientifiques de niveau recherche, publiés ou non, émanant des établissements d'enseignement et de recherche français ou étrangers, des laboratoires publics ou privés.

$$
\text { Copyright }
$$




\title{
Synthetic Genes Specifying Periodic Polymers Modelled on the Repetitive Domain of Wheat Gliadins: Conception and Expression
}

\author{
Khalil Elmorjani, ${ }^{*},{ }^{1}$ Marina Thiévin,*,† Thierry Michon,* \\ Yves Popineau,* J ean-N oel Hallet, $\dagger$ and J acques Guéguen* \\ *Laboratoire de Biochimie et de Technol ogie des Proténes, INRA, BP 1627, 44316 Nantes Cedex, France; and \\ tUnité de Biocatalyse, UPRES 2161 Faculté des Sciences et des Techniques, Université de Nantes, \\ 2 rue de la Houssinière, BP 92208, 44072 Nantes Cedex 03, France
}

Received August 28, 1997

In order to optimise new polypeptide based biomaterials, we developed a procedure for producing homoblock polypeptides using recombinant DNA technology. Synthetic genes encoding periodic polypeptides modelled on the consensus sequence of wheat gliadins (a family of wheat storage proteins) were devised to be expressed in Escherichia coli. The construction strategy followed allows the construction of three genes encoding 8, 16, and 32 copies of the PQQPY module. The optimal expression conditions in the enterobacteria were established and a convenient purification procedure was shown to be useful in recovery of sizable amounts of strictly periodic polypeptides. The identities of the synthesized polypeptides were assessed using positive cross reactions to antibodies raised against a synthetic decapeptide (PQQPYPQQPA) and amino acid composition was determined as well. 1997 Academic Press

Key Words: synthetic genes; wheat gliadins; periodic polypeptides; expression; Escherichia coli.

In the course of evolution, the nature optimized protein based biomaterials possessing remarkable properties (1). Among these are the fibrous proteins found in the animal kingdom such collagen (2), keratin (3), elastin (4) or silk from insects and spiders $(5,6)$. All these proteins display a common feature : they consist primarily in repetitive ol igopeptide sequences which, individually, have little defined secondary structures. Once polymerized by mean of peptide bounds the increasing number of these blocks leads to a secondary folding of the peptide chain through $\alpha$ backbone hydrogen bond-

\footnotetext{
${ }^{1}$ Corresponding author. Fax: (33) 240292 042. E-mail: elmorjan@ nat.svt.sciences.univ-nantes.fr.
}

ing and finally to self associations into supramolecular structures through sidechain interactions. Protein networks thus formed display very specific physical properties such as collagen gelification or keratin resistance to a tensile strength. A special mention should be delivered to the elastomeric protein based polymer $(G V G V P)_{n}$ which can exist as hydrogel or in elastic and plastic states $(7,8)$. Therefore, this is the primary structure of peptides which finally determines very specific properties of the ending biomaterials, as it is the case for synthetic polymers.

"Prolamins" term refers to cereal storage proteins, a highly complex protein group, which account for up to $50 \%$ of total seed proteins (9). The primary structures of prolamins have in common a domain consisting of repeated amino acid blocks. This structural feature recalls that displayed by animal fibrous proteins and distinguishes them from non-prolamin proteins. These repeated sequences together with disulphide bonds (the basis of the cross-linked protein matrix) are responsible for the visco-elastic properties of gluten, a protein network formed when wheat flour is hydrated and mixed into dough (10). The prolamins focus attention not merely for their functional properties in food systems (11) but al so because they can be suited to new applications as substitute to polymers synthesized from fossil resources $(12,13)$. A wide range of experimental processing (hydrolysis, chemical and physical modifications or fractionation procedures) have been developed to achieve for instance mechanical and barrier properties for packaging applications of gluten-based materials $(14,15,16)$. These bi opol ymer films remain however ill-suited and many difficulties have to be iron out in order to improve their mechanical performances. Indeed, in addition to their sensitivity to moisture and to their intrinsic weak water resistance, engineered gluten based materials abut also against its structural 
complexity. It is self evident that the extreme heterogeneity of the protein forming gluten and the uneven distribution of residues lead to conflicting polarity limiting its usefulness as a genuine substitute to some petrochemical polymers (15). Indeed, at least a hundred different proteins, varying in size but with roughly close physico-chemical properties, accumulate in the wheat endosperm. This makes extremely arduous the purification of individual homogeneous proteins. Consequently the determination of their actual contributions to mechanical properties of gluten remains questionable (10).

Today, the efficiency of recombinant bacterial expression systems and the relative ease to construct artificial genes offer the expediency to overcome these limitations. Our aim is to experiment with the physical properties (mechanical, barrier properties . . .) of materials fashioned from the repeated domains. We decided therefore to design and massively produce in bacteria periodic polypeptides tailored on the consensus repeated amino acid sequence of wheat gliadins.

Optimal expression conditions in E. coli as well as a purification procedure were established. Such polymers, used as backbones, may lead to confection of potentially suitable biomaterials owing to the opportunity to flanck them ad lib with grafting motifs. Additionnally, the availability of periodic polypeptides should allow us to grasp the actual contribution of this domain in the mechanical properties of this class of prolamins.

\section{MATERIAL AND METHODS}

Genetic construction procedure was processed in J M109 E. coli strain ( $F^{\prime} \operatorname{traD}_{6} \mathrm{Iacl}^{\mathrm{q}} \mathrm{Z} \triangle \mathrm{M} 15$ proAB e14- (mcrA ${ }^{-}$) recA1). Expression experiments were conducted in M 15 (pREP4) (Nal ${ }^{\mathrm{S}} \mathrm{Str}^{\mathrm{S}} \mathrm{rif}^{\mathrm{S}}$, $\mathrm{Iac}^{-}$ ara $\left.^{-} \mathrm{gal}^{-} \mathrm{mtl}^{-} \mathrm{F}^{-}\right), \mathrm{HMS174}$ (pLysS) (F- recA hsdR $\left(\mathrm{r}_{\mathrm{k} 12^{-}} \mathrm{m}_{\mathrm{k} 12+}\right) \mathrm{Rif}^{\mathrm{r}}$ (DE3) pLysS, cmrr) E. coli K 12 strains and in the host cell line BL21 (pLysS) strain (F- ompT hsdS ${ }_{B}\left(r_{B}-m_{B+}\right)$ gal dcm (DE3) pLys, Cmr $)$. High copy number plasmid pBluescript $\mathrm{SK}^{+}$was used as a construction vector as detailed in result section. Competent cells of $E$. coli were prepared by the methods described in Ausubel et al.(17) and cells were transformed either by the TSS procedure or by electroporation (17).

LB medium was used for routine growth and the terrific broth (TB) which allow growth to high cell densities was used during expression experiments. Carbenicillin and Chloramphenicol (SIGMA) were added to media at concentrations of 100 and $25 \mu \mathrm{g} / \mathrm{ml}$ respectively. LacZ indicator plates contained 5-bromo-4-chloro-3-indolyl $\beta$-D galactoside (X-gal) at $20 \mu \mathrm{g} / \mathrm{ml}$. IPTG (Eurobio) was added at 0.4 to 1 $\mathrm{mM}$. The standard recombinant DNA methods followed were essentially as reported by Ausubel et al. (17) and by Sambrook et al. (18). Small-scale plasmid preparations were done according to (19). For more purified plasmids, the cleared cell lysates were loaded onto QIAGEN-tips packed with the QIAGEN resin. DNA fragments were extracted from PAGE according to Sambrook et al. (18) and from agarose gels by using the Qiaex Kit (Qiagen). Restriction endonucleases were purshased from Boehringer Mannheim and synthetic oligonucleotides were from Eurogentec. DNA sequencing was performed by the dideoxy sequencing method of Sanger et al. (20) using double stranded DNA as template and universal primers or synthetic oligo- nucleotides as primers for modified T7 DNA polymerase (Sequenase US Amersham).

Optimal expression conditions were established during this study (see results). Single colonies were used to inoculate an overnight culture of LB carbenicillin/chloramphenicol. The cells were then diluted 100-fold into fresh TB medium containing the antibiotics and the cultures were incubated on a rotary shaker at $30^{\circ} \mathrm{C}$. When cell density monitored by optical density at $600 \mathrm{~nm}$ attained 2.5, IPTG was added at 0.4 or $1 \mathrm{mM}$. Cultures were maintained under these induction conditions for 2 and 3 hours. Cells are then collected by centrifugation $(1000 \mathrm{~g}, 5 \mathrm{~min}$ ) washed once with the binding buffer (I midazole 5mM, Nad 500 mM, Tris- $\mathrm{HCl} 20$ mM; pH 7.9) and resuspended in the same buffer. The samples were subject to sonication and the subsequent lysate was clarified by centrifugation (15000 t. $\left.\mathrm{min}^{-1} ; 30 \mathrm{~min}\right)$. The resulting supernatants were directly applied to a $\mathrm{Ni}^{++}$resin column under non-denaturing conditions. When required, the buffers were supplemented with urea (6M) as a denaturing agent. The QI Aexpress Ni-NTA protein purification system was purchased from Qiagen and the purification procedure was conducted as recommended by the manufacturer.

Once collected, the eluates were submitted to a reverse phase chromatography to remove the imidazole and the samples recovered were frozen dried. The fusion proteins were then processed in order to release the repetitive polypeptides. The samples were either dissolved in tris/ $\mathrm{HCl} 20 \mathrm{mM}$ pH 8.5 for trypsin attack (enzyme/substrate ratio $1 / 100 \mathrm{w} / \mathrm{w}$ ) or in $70 \%$ formic acid for $\mathrm{BrCN}$ cleavage $(\mathrm{BrCN} /$ protein $5 / 1 \mathrm{w} / \mathrm{w}$ ). Proteolysis was performed at $30^{\circ} \mathrm{C}$ during 12 hours. The resulting samples were then loaded on a C18 LiChroCART 2504 Superspher $(0.4 \times 25 \mathrm{~cm}$, porosity $100 \mathrm{~A})$ collumn Merck, Darmstadt, Germany, previousely equilibrated in an A medium containing $0.06 \%$ TFA in water. After a 6 min wash, the compounds were eluted with a B medium containing $75 \%$ acetonitrile and $0.04 \%$ TFA. A 0 to $100 \%$ $B$ gradient was applied in $30 \mathrm{~min}$, flow rate $1 \mathrm{ml} / \mathrm{min}$. This gradient achieved to separate all the major compounds obtained after processing of the protein fusions. Each fraction containing the repetitive polypeptide was recovered and frozen dried. Absorption experiments were made as described by Michon et al. (21) and the spectra were recorded using a Cary13E model spectrophotometer 5Varian, Australia).

SDS-PAGE were done according to Laemmli (22). I mmunoblotting and revelation experiments were performed as described in (23).

\section{RESULTS AND DISCUSSION}

To control tightly the length of repeats and to select genes allowing optimal overexpression product we opted for a construction approach based on the amplification by direct repetition of a basic oligonucleotide.

The pentapeptide PQQPY represents a consensus sequence of the wheat gliadin repetitive domain (8) and was chosen as a basic unit. Figure $1 \mathrm{~A}$ shows the primary structure of the starting double strand (ds) oligonucleotide encoding this module. The need in the amplification procedure for blunt ends endonuclease sites, implies the use of CCT and TAC codons to specify the flanking residues, $P$ and $Y$ respectively. These codons are indeed involved in the recognition sequences of the endonucleases Stul and SnaBl which fit with another essential condition, they do not cut the construction vector (Bluescript SK plasmid). The internal three amino acids $\mathrm{P}, \mathrm{Q}$ and $\mathrm{Q}$ are specified by the CAG, CAA and CCG codons respectively. The ds oligonucleotide contains also an ATG codon, designed in conjunction with a $\mathrm{Ncol}$ endonuclease site in such a way that the double digestion $\mathrm{N}$ col/Stul followed 
A:

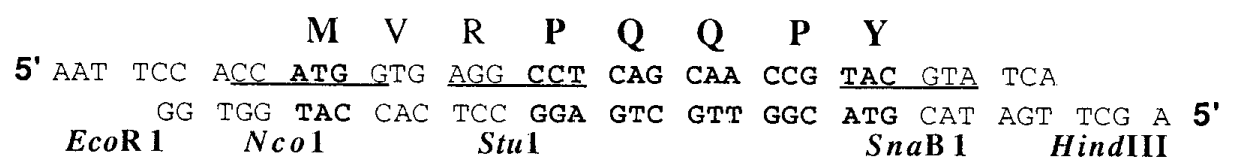

B :
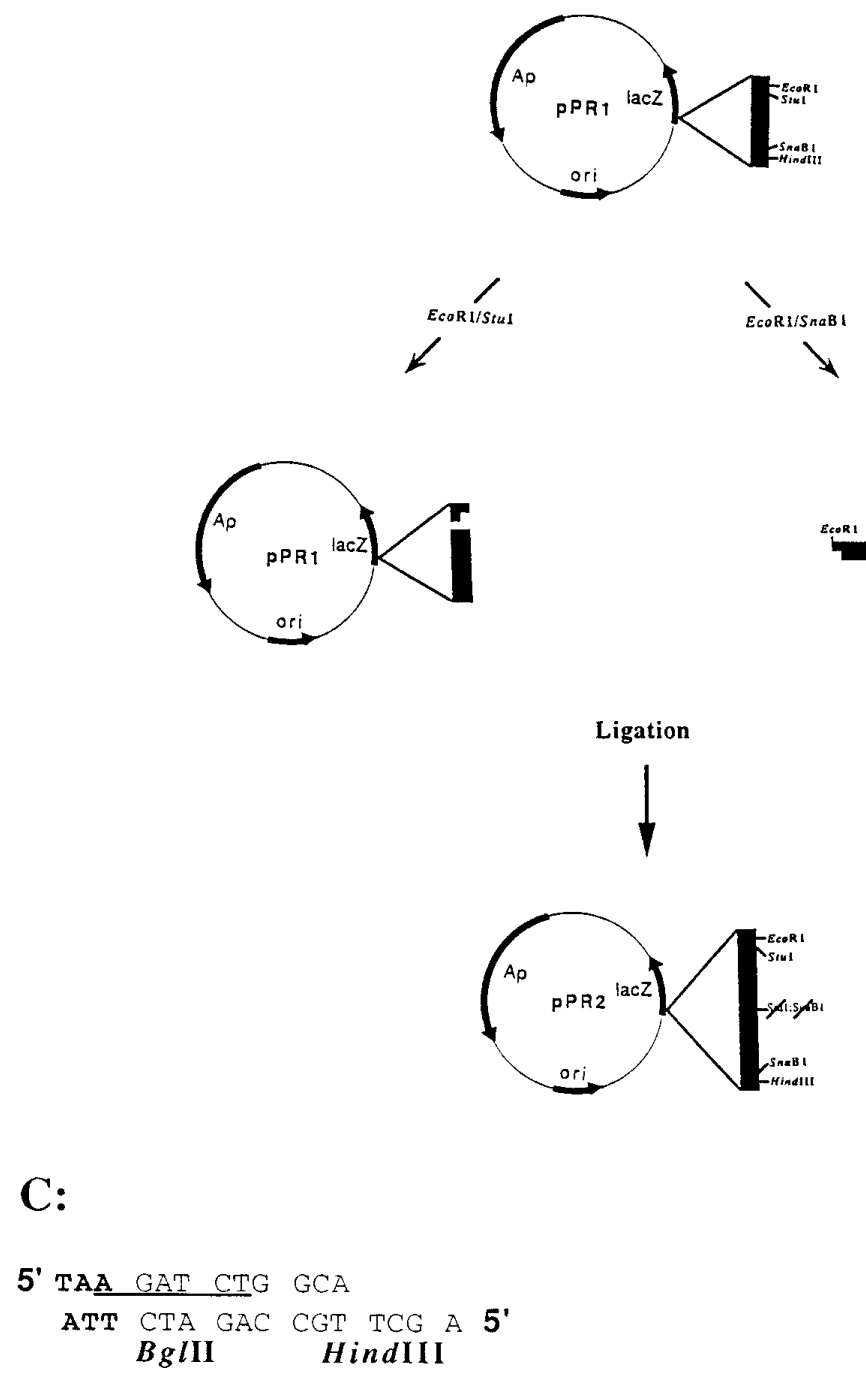

FIG. 1. (A) Primary structure of the designed double strand oligonucleotide encoding the pentapeptide PQQPY. (B) I terative procedure followed to amplify the starting module by direct repetition. $\mathbf{a}$ represents the EcoR $1 / S$ naB 1 fragment (see A).

by the fill-in of the resulting cohesive end and ligation lead to the setting of the ATG codon immediately at the $5^{\prime}$ end of the CCT of the first repeat. Finally the double strand oligonudeotide was flancked with the commonly used endonudease sites EcoRI and HindIII required for the construction procedure but also to make easier the handling of the synthetic genes from one expression vector system to another.
To enhance the stability of repetitive sequences, the synthetic oligonucleotide duplex was inserted in lac Z gene. Indeed, the length of the basic oligonucleotide was determined to allow its insertion in frame in the bluescript lacZ gene. This option extends the experimental convenience of the lac genetic system to the construction procedure by greatly facilitating the detection of any colony defective in $\alpha$ complementation, sub- 
ject to genetic instability and as such appears white on the LacZ indicator plates when checked for $\beta$-galactosidase activity. The effective insertion of the oligonucleotide in PPR1 plasmid was confirmed by the acquisition of Stu1, Ncol and SnaB 1 endonuclease sites and by the release of a 39bp fragment following plasmid digestion with both EcoR 1 and HindIII.

The procedure followed to build plasmids encoding up to 32 repeats of the basic unit is diagrammatically summarized in figure 1B. To reduce the effort required in recovering the desired recombinant plasmids, we systematically resort to polyacrylamide and agarose gel electrophoresis in order to purify both the DNA fragments to be inserted and the appropriate plasmids generated by restriction endonuclease double digestions.

The procedure consists in the use of pairwise combinations of three restriction enzymes (EcoRI, Stul and SnaB1) allowing appropriate directional cloning. Purified $E c 0 R 1 / S n a B 1$ fragment from the pPR1 plasmid was ligated with purified pPR 1 plasmid which has been cleaved with EcoR1/Stu1 endonudeases. This directional insertion allowed the repetition of the first structural unit coding sequence and the abolition of both Stul and SnaBl endonuclease sites at the junction of the two blunt ends. Conversely, these two cleavage sites are still present at the $5^{\prime}$ and $3^{\prime}$ ends of what became now a double copy of the starting module. The resulting plasmid, PPR2, encodes thus a decapeptide (PQQPYPQQPY) buried in the N-terminus of $\alpha$ fragment of $\beta$-galactosidase. Repeating the same procedure several times leads to the construction of pPR8 16 and 32 encoding respectively 8,16 and 32 copies of the PQQPY pentapeptide, which are selected for further characterization.

A double strand oligonucleotide (figure 1C) carrying a stop codon (TAA) at its $5^{\prime}$ end (blunt end) and at its $3^{\prime}$ end a cohesive end designed to be inserted at Hindl II was cloned in SnaB1/Hindlll digested pPR8, 16 and 32 plasmids. This oligonucleotide carries also a Bglll endonuclease site. This last feature, in addition to the loss of SnaB1 restriction site, allows the retention among the recombinant plasmids recovered those that have effectively integrated the stop codon since this endonuclease does not cut the construction plasmid. A $\beta$-gal ${ }^{-}$phenotype, due to interruption of lacZ (white col ony phenotype), allows first to eliminate all the plasmids that did not integrate the ds oligonucleotide. The validity of the genetic constructions was finally confirmed by sequencing. The genes encoding 8, 16 and 32 times the PQQPY pentapeptide were named spr8, spr 16 and spr32 respectively. Since high expression is vector and strain dependent and because it is deeply affected by culture conditions, the main parameters governing the spr gene expression levels in $\mathrm{E}$. col i were investigated and optimal expression conditions as well as a purification procedure were established. The results of such an analysis is given in figure $2 \mathrm{~A}$ and $2 \mathrm{~B}$.
As first step, spr genes were cloned in two different expression vectors under the control of either the T7 or T5 promoters. The three spr genes were excised as $\mathrm{Ncol} / \mathrm{Hindl}$ II fragment and ligated in a pQE expression plasmid (Qiagen) under the control of the T5 promoter. The resulting plasmids (pQE8s, pQE16s and pQE 32s) were transfered in the M 15 expression host strain. Under the control of the T7 promoter the synthetic genes were also inserted as $\mathrm{Ncol} / \mathrm{Hindl}$ II fragments in the pET21d (N ovagen). Subsequently, to set the ATG codon immediately upstream to the CCT codon of the first repeat, the plasmids were cleaved with $\mathrm{Ncol}$ and Stul endonucleases and purified. These linearized plasmids were then treated with the Klenow fragment of DNA polymerase in the presence of dNTP in excess to generate compatible ends. After ligation, the resulting plasmids named pETd8sF, pETd16sF and $\mathrm{pETd}$ T2sF were introduced in E. coli HMS expression host strain. When both the T7 and T5 promotors driving directly the spr 8, spr 16 and spr 32 gene expression were induced in HMS and in M15 E. coli K12 strains, levels of the polypeptides were very low. In both cases, recombinant polypeptides around 40, 80 and 160 residues were detected only after crossreaction with antibodies raised against a synthetic PQQPYPQQPA decapeptide (data not shown). Heterologous overproduction in $\mathrm{E}$. coli of unstructured periodic polypeptides comes up frequently against intracellular proteolysis $(24,25)$. In order to verify whether the recombinant polypeptides are sitting target of rapid degradation, the $3 \mathrm{pET}$ plasmids were transfered into the host cell line BL21 (DE3) (pLysS), an E. coli strain B lacking the major proteases(Ion and ompT) of K12 strain. Notwithstanding a slight improvement of the expression levels the amounts of the bi opolymers produced remain lower than those expected and are not consistent with the well known strong T7 promoter (26). Restriction analysis of the isolated plasmids showed that no recombination or deletion events have occured during the induction periods. Moreover, the fact that the recourse to E. coli BL 21 strain as expression host did not appreciably enhance the accumulation of the periodic polypeptides, indicates that, under these experimental conditions, this failure is not the result of an extensive proteolysis. Alternatively, owing to their peculiar primary structures, it is not unlikely that the spr transcripts form umpropitious secondary structures which in turn affect markedly their translational efficiency. We decided therefore to express the periodic genes as C-terminal translational fusion with E. coli thioredoxin (trxA encoding TRX protein). This expression system (pET system) has been used successfully to produce soluble target proteins which are otherwise insoluble in E. coli (27).

The three spr genes were excised, once more, as $\mathrm{Ncol} / \mathrm{HindlII}$ fragments and directly inserted into pETbTRX vector, downstream the trxA gene. As de- 

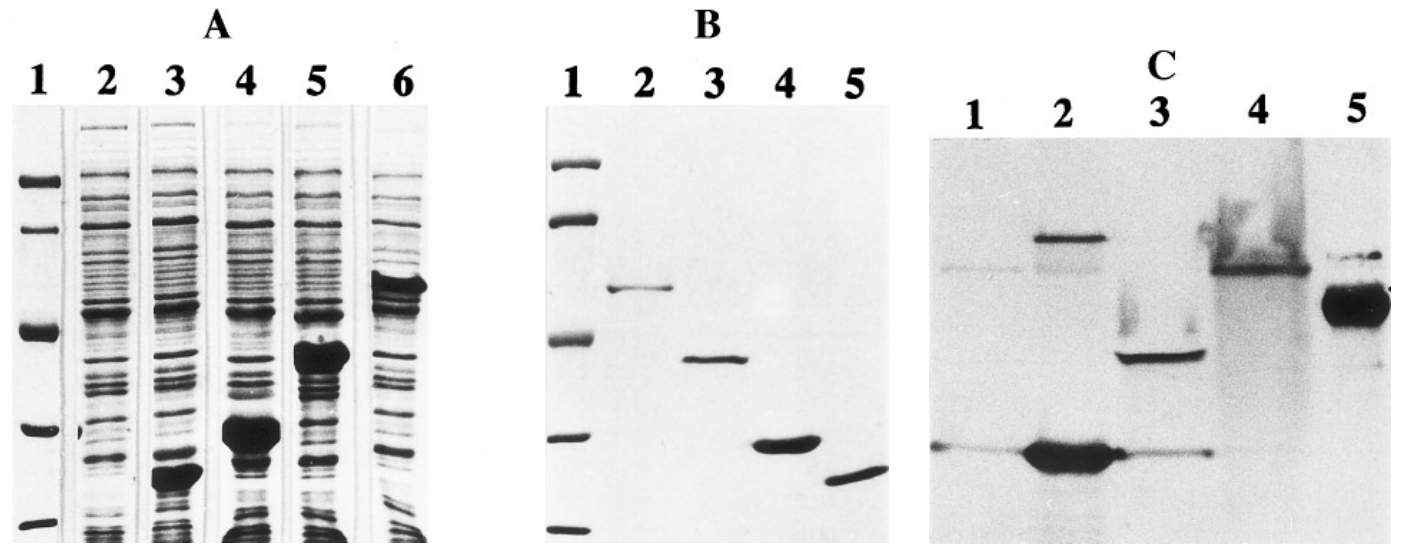

FIG. 2. SDS-page (10\%) stained with Coomassie blue after electrophoresis of: (A) total proteins extracted from BL 21 (DE) pLysS E. coli strains carrying (2) pETbTRX (uninduced); (3) pETbTRX; (4) pETb8s; (5) pETb16s ; and (6) pETb32s; 3 hours after IPTG addition. (1) Standard molecular weight markers from BioRad (from top to bottom : 97.4, 66, 45, 31, 21.5 and $14.5 \mathrm{kDa}$ ). (B) purified fusion proteins after elution through a Nickel -chelation column. (1) Standard molecular weight markers; (2) TRX/SPR32; (3) TRX/SPR16; (4) TRX/SPR8 fusion proteins and (5) TRX protein. (C) Western-blot of induced fusion products and thioredoxin polypeptide. (1) TRX polypeptide; (2) TRX/ SPR8; (3) TRX/SPR16; (4) TRX/SPR32 and (5) standard molecular weight markers. The positive band detected in this lane corresponds to serum albumin polypeptide.

scribed above, the two codons GTG and AGG located between the ATG codon and the first repeat were eliminated, and the resulting expression plasmids were termed pETb8sF, pETb16sF and pETb32sF. These plasmids were used to transform E. coli BL21 strain and the expression of the fusion genes was induced by addition of IPTG. Sonicated whole cell lysates from induced and uninduced samples were analyzed by SDSPAGE (figure 2A). The induction of the T7 promoter resulted in the expression of three new polypeptides (lanes 4, 5 and 6) with increasing apparent Mr when compared to the induced thioredoxin (lane 3) used here as control. Under these translational conditions the overexpression of the periodic polypeptides is obvious as indicated by band intensities at the expected sizes. Typically, TRX/SPR8 and TRX/SPR 16 account for $20 \%$ of total E. coli proteins while TRX/SPR 32 polypeptide represents $15 \%$. Thus, the expression fusion strategy appears to have remedied the translational problems encountered previously. The expression of the fusion polypeptides resulted in accumulation of soluble materials, except for a non-negligible part of the TRX/SPR 32 protein. Indeed, this fusion protein has some tendency to form insoluble inclusion bodies and as such requires an additional solubilisation step to achieve exhaustive extraction.

Accumulation in E. coli of heterologous over-expressed protein can be affected by intracellular proteolysis $(28,29)$. Seemingly, the fusion products remain susceptible to in vivo proteolytic activities since attempts to overproduce these in HMS E. coli strain carrying the same genetic constructions resulted in a drastic drop of accumulation of these polypeptides (not shown). Consequently, trx/spr genes have to be expressed in BL21 strain.
The expression level of TRX/SPR protein fusions in E. coli BL21 is dependent upon the length of the periodic polymers. Indeed, while the TRX/SPR8 and TRX/ SPR16 fusion proteins are expressed roughly at an equivalent high level, the TRX/SPR32 is clearly accumulated at a lesser one (figure 2A). It is not excluded however that this last fact might be related, at least in part, to the unavoidable loss inherent to solubilization of the TRX/SPR32 protein forming inclusion bodies. In addition, induction temperature was proved to be an important parameter to achieve high level expression. Indeed, the expression of TRX/SPR fusion encoding genes was found to be optimal at $30^{\circ} \mathrm{C}$ and drastically affected by higher temperatures.

In order to purify the protein fusions clarified lysates from induced pETb8sF, pET16sF and pET32sF containing cells were loaded on an affinity column. Owing to the 6 consecutive histidine residues located downstream to the thioredoxin polypeptide, the fusion proteins are selectively retained on a $\mathrm{Nickel-chelation} \mathrm{col-}$ umn and eluted by increasing the imidazole concentration. Figure 2B illustrates the efficiency of such purification procedure. The apparent $\mathrm{Mr}$ of 27, 39 and $53 \mathrm{kDa}$ for respectively TRX/SPR8, TRX/SPR 16 and TRX/SPR32 purified fusion polypeptides are rather overestimated in regard to the calculated Mr. These sizes are however consistent with the anticipated TRX/ SPRX fusion proteins. Indeed, these apparent discrepancies are clearly exacerbated by the length of the repetitive domains, being more pronounced in the case of the TRX/SPR 32 than in the case TRX/SPR8 polypeptides. This was expected since native prolamins and synthetic glutenin have been shown to exhibit typical peculiar SDS-PAGE behaviors attributed precisely (or at least for a large part) to their repetitive domains 
(30, 31, 32). The identities of the synthesized fusion proteins were confirmed, after western blotting, by positive cross-reactions with antibodies directed against a synthetic decapeptide (figure 2C, lanes 2, 3 and 4).

Once purified the fusion proteins were submitted to processing in order to recover the periodic polypeptides. This was achieved by two different cleavage procedures. As the fusion proteins contain five Met residues, the cyanogen bromide $(\mathrm{CNBr})$ gave rise to six fragments one being the repetitive polypeptide. When trypsin cleavage was used to recover such strictly periodic polypeptides, the expression experiments were performed with cells harboring pETb8s, pETb16s and pETb32s (the non fill-in plasmids). Indeed, only these genetic constructions have an arginine residue located immediately upstream of the first repeat. Figure $3 \mathrm{~A}$ shows an HPLC profile of the TRX/SPR8 protein after trypsin cleavage. The major peak resolved around 13 min corresponds to the SPR 8 polypeptide since the UV spectrum of this collected fraction matches perfectly to the one obtained from the synthetic decapeptide PQQPYPQQPA (Figure 3B). In addition, absorption spectra maxima shifted from $276.4 \mathrm{~nm}$ at acidic $(\mathrm{HCl} 0.1 \mathrm{~N})$ to $293 \mathrm{~nm}$ at alcalin $\mathrm{pH}(\mathrm{NaOH} 0.1 \mathrm{~N})$ (not shown). This feature is a caracteristic of ionisation of the phenolic function carried by the tyrosine residues. Further, amino acid composition was found to be consistent with the expected composition of the designed polypeptide (not shown). Assuming an extinction coefficient of 1320 $\mathrm{M}-1 \mathrm{~cm}-1$ at $278 \mathrm{~nm}$ and $\mathrm{pH} 7$ per tyrosine residue it was possible to estimate the recovery of the recombinant peptide. Typically, starting from $20 \mathrm{ml}$ culture, $100 \mu \mathrm{g}$ of pure SPR 8 polypeptide were recovered. This yield was confirmed when the polypeptides were purified starting from $300 \mathrm{ml}$ culture.

The results presented here show clearly that the iterative controlled procedure followed to build periodic genes, in lac $Z$ gene, is very powerful. The usefulness of this construction strategy is demonstrated by the permissivity of the constructs in such a way that intermediate constructs as well as larger polymers can be devised with the utmost ease, by simply ligating the appropriate DNA fragments. The parameters allowing efficient expression levels were optimized and a purification procedure was shown to be extremely convenient. We are currently investigating the physical properties of these purified periodic polypeptides. The main objective of our work is to experience in fine the mechanical properties of biomaterials tailored as PQQPY homoblock biopolymers. The particular care taken over keeping the genetic constructs permissive for the insertion of different peptide sequences should be construed through this objective. The polymerized spr genes can thus be readily handled, so as different sequences encoding target amino acids for grafting enzymes (transglutaminases, peroxydases . . . .) or simply cystein residues (disulfide crosslinking) could be inserted at the 5'
A

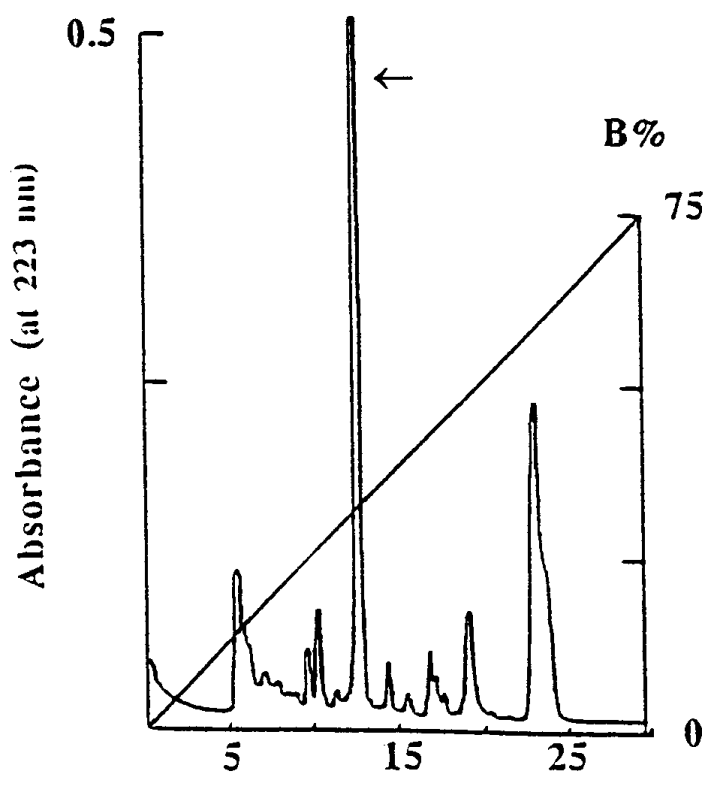

Time (min)

B

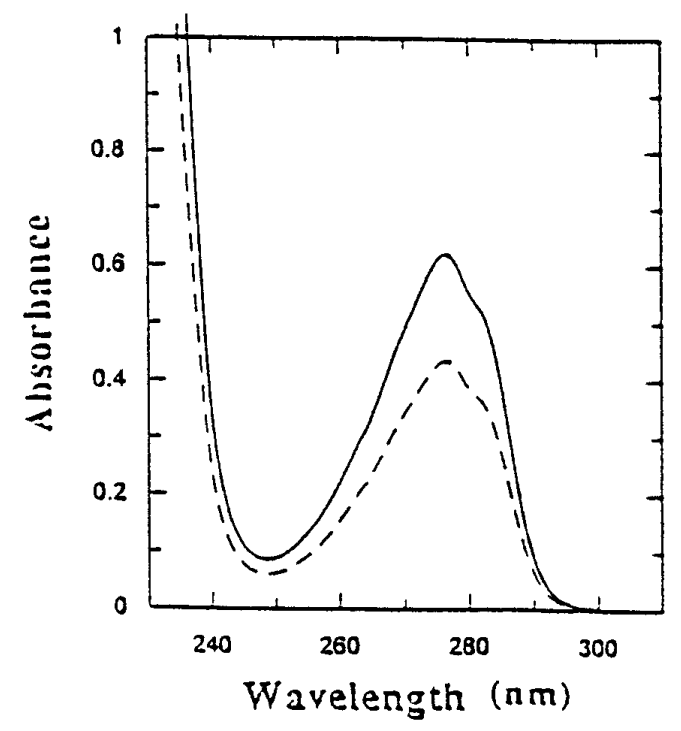

FIG. 3. (A) Elution profile of the TRX/SPR8 polypeptide digested with trypsin. The chromatography was performed as described in the materials and methods section. The arrow indicates the fraction corresponding to the SPR8 periodic polypeptide. (B) UV spectra of recombinant and synthetic peptides resuspended in water. (-) purified SPR8 peptide $(40 \mu \mathrm{M}),(---)$ synthetic decapeptide PQQPYPQQPA $(500 \mu \mathrm{M})$.

and/or the $3^{\prime}$ ends of these genes or in case of need between two repetitive domains. In addition, inserted in a gliadin non repetitive domain template, the spr 
genes will lead us to determine in which way and to what extent the repetitive domains are underlying the mechanical properties of the native proteins.

\section{ACKNOWLEDGMENTS}

\begin{abstract}
We are grateful to all our colleagues at LBTP for their stimulating discussions and support, especially S. Denery Papini and L. Quillien for providing us with the antibodies and technical advice in performing the Western blot. Many thanks are extended to J . Fleurent for correcting our manuscript. K.E. is supported by grants from " $\mathrm{La}$ Région Pays de Loire" and ECC/FAIR programme. M.T. is the recipient of a fellowship from the French MESR. This work was supported by La Région Pays de Loire, INRA, and ECC/FAIR programme.
\end{abstract}

\section{REFERENCES}

1. Cappello, J ., Crissman, J ., Dorman, M., Mikolajczak, M., Texor, G., Marquet, M., and Ferrari, F. (1990) Biotechnol. Prog. 6, 198202.

2. Thomas, J . T., Cresswell, C. J ., Rash, B., Nicolai, H., J ones, T., Solomon, E., Grant, M. E., and Boot-Handford, R. P. (1991) Biochem. J . 280, 617-623.

3. Steinert, P. M., Rice, R. H., Roop, D. R., Trus, B. L., and Steven, A. C. (1983) Nature 302, 794-800.

4. Venkatachalam, C. M., and Urry, D. W. (1981) Macromol. 14, 1225- 1231.

5. Fraser, R. D. B., Mac Rae, T.P., and Stewart, F.H. (1966) J . Molec. Biol. 19, 580- 582.

6. Xu, M., and Lewis, R. V. (1990) Proc. Natl. Acad. Sci. USA 87, $7120-7124$.

7. Guda, C., Zhang, X., McPherson, D. T., Xu, J., Cherry, J.H., Urry, D. W., and Daniell, H. (1995) Biotechnol. Ietters. 17, 745750.

8. Urry, D. W. (1995) Scientific American. 272, 64- 69.

9. Shewry, P. R., Miles, M. J ., and Tatham, A. S. (1994) Proc. Biophys. Molec. Biol. 51, 37-59.

10. Shewry, P. R., Tatham, A. S., Barro, F., Barcelo, P., and Lazzeri, P. (1995) Bio/ Technology 13, 1185- 1190.

11. Torrès, J. A. (1994) in Protein Functionality in Food Systems (Hettiarachchy, N. S., and Ziegler, G. R., Eds.), pp. 467-507. Dekker, New York.

12. Miles, M. J ., Carr, H. J ., McMaster, T. C., I'Anson, K. J ., Belton,
P. S., Morris, V. J ., Field, J . M., Shewry, P. R., and Tatham, A. S. (1991) Proc. Natl. Acad. Sci. USA. 88, 68-71.

13. Kasarda, D. D. (1994) in Molecular Modeling: From Virtual Tools to Real Problems (Kumosinski, T. F., and Liebman, M. N., Eds.), pp. 209-220. Am. Chem. Soc., Washington, DC.

14. Donhowe, I. G., and Fennema, O. (1994) in Edible Coatings and Films to Improve Food Quality (Krochta, J . M., Baldwin, E. A., and Nisperos-Carieda, M. O. Eds.), pp. 1-24. Technomic, Lancaster, PA.

15. Rothfus, J . A., and Hagemann, J . W. (1994) J . Agric. Food Chem. 42, 909-914.

16. Ezpeleta, I., I rache, J . M., Staimesse, S., Chabenat, C., Guéguen, J ., and Orecchioni, A. M. (1995) Int. J . Pharm. 131, 191-200.

17. Ausubel, F. M., Brent, R., Kingston, R. E., Moore, D. D., Seidman, J. G., Smith, J . A., and Struhl, K. (1989) Current Protocols in Molecular Biology, Wiley New York.

18. Sambrook, J ., Fritsh, E. F., and Maniatis, T. (1989) Molecular Cloning: A Laboratory Manual, 2nd ed. Cold Spring Harbor Laboratory Press, Cold Spring Harbor, NY.

19. Birnboim, H. C., and Doly, J . (1979) Nucl. Acids Res. 7, 15131523.

20. Sanger, F., Nicklen, S., and Coulson, A. R. (1977) Proc. Natl. Acad. Sci. USA 74, 5463-5467.

21. Michon, T., Chenu, M., Kellershon, N., Desmadril, M., and Guéguen, J . (1997) Biochemistry. 36, 8504- 8513.

22. Laemmli, U. K. (1970) Nature 227, 680-685.

23. Denery-Papini, S., Briand, J . P., Quillien, L., Popineau, Y., and Van Regenmortel, M. H. V. (1994) J . Cereal Sci. 20, 1- 14.

24. Parsell, D. A., and Sauer, R. T. (1989) J . Biol. Chem. 264, 75907595.

25. Schein, C. H. (1989) Bio/ Technology. 7, 1141- 1149.

26. Studier, F. W., Rosenberg, A. H., Dunn, J.J ., and Dubendorff, J. W. (1991) Methods in Enzymol. 185, 60-89.

27. La Vallie, E. R., DiBlasio, E. A., Kovacic, S., Grant, K. L., Schendel, P. F., and McCoy, J. M. (1993) Bio/ Technol. 11, 187- 193.

28. Gottesman, S. (1989) Annu. Rev. Genet. 23, 163- 198.

29. Gottesman, S. (1991) Methods Enzymol. 185, 119- 128.

30. Goldsbrough, A. P., Bulleid, N. J ., Freedman, R. B., and Flavell, R. B. (1989) Biochem. J . 263, 837-842.

31. Anderson, O. D., Kuhl, J . C., and Tam, A. (1996) Gene 174, 5158.

32. Bunce, N., White, R. P., and Shewry, P. R. (1985) J . Cereal Sci. 3, 131- 142. 